\author{
Álvaro Martín Navarro* \\ Kansai Gaidai University (Hirakata, Japón) \\ almanavar@yahoo.com
}

\title{
La crónica del desencanto en la obra Sensaciones de Japón y China de Arturo Ambrogi**
}

The chronicle of Disenchantment in the Book Sensaciones de Japón y China, by Arturo Ambrogi

Crônica de desencanto no Livro Sensaciones de Japón y China, por Arturo Ambrogi

* Profesor asociado a la Universidad Kansai Gaidai de Hirakata, Japón.

** Este artículo es producto de la investigación sobre la construcción del imaginario del "Lejano Oriente" en la obra de Arturo Ambrogi, en el marco de una investigación documental que busca mostrar las diversas percepciones en las crónicas y narraciones de los primeros latinoamericanos que llegaron a Japón, en este artículo se da una aproximación de la obra de Arturo Ambrogi. La investigación contempla el análisis de la obra de seis autores.

Artículo de reflexión: recibido 08/09/2014 y aprobado 29/11/2014 



\title{
Resumen
}

Arturo Ambrogi visitó Japón en las primeras décadas del siglo XX. No fue como diplomático ni como corresponsal de prensa ni como escritor profesional, sino como observador, cronista y aventurero. Ambrogi pudo percibir y narrar elementos que otros cronistas latinoamericanos que estuvieron en Japón (como Enrique Gómez Carrillo, Efrén Rebolledo, José Juan Tablada), no pudieron apreciar, o por lo menos pasan desapercibidos en sus narraciones. Las crónicas de Ambrogi son una visión de Japón no como "lugar exótico", para satisfacer un imaginario colectivo, sino como un país transformándose en emporio industrial y turístico, desnudando las raíces de un Imperio cuya cultura se occidentaliza a través de las modas y la vulgaridad.

Palabras clave: Arturo Ambrogi, Japón, Crónicas, Turismo.

\begin{abstract}
When Arturo Ambrogi visited Japan in the early twentieth century, he did not go as a diplomat, a journalist, or a writer. He went as a chronicler, an adventurer, and an observer. Hence, Ambrogi could perceive and narrate elements that other Latin American writers, who also shared their stories of Japan, could not. The chronicles of Ambrogi is not another vision of Japan as an "exotic" country that match a typical collective imagination of the time, but they are about a country that shows progressive transformations towards becoming an industrial empire and a tourist destination. The chronicles also set down the roots of an empire which culture is westernized through fashion and vulgarity.
\end{abstract}

Key words: Arturo Ambrogi, Japan, Chronicles, Tourism.

\section{Resumo}

Arturo Ambrogi visitou o Japão no início do século XX. Ele Não sofreu ir como um diplomata, jornalista, ou um escritor, ele foi como um cronista, aventureiro e observador. Ambrogi podia perceber e narrar elementos outros escritores latino-americanos que estavam no Japão (como Enrique Gómez Carrillo, Efren Rebolledo e José Juan Tablada) não poderia, ou pelo menos em suas histórias esta passar despercebida. As crônicas de Ambrogi são uma visão do Japão não como “exótico", que satisfazer um imaginário coletivo, mas como um país que mostra as transformações progressistas como um império industrial e um destino turístico.

Palavras-chave: Arturo Ambrogi, Japão, Crônicas, Turismo. 

Hasta estos últimos años era inaccesible a los europeos, misteriosa; hoy se va en ferrocarril, lo cual significa que ha llegado a vulgarizarse, a decaer, a extinguirse. Desde Kobe se puede ir a la ciudad en trenes casi rápido, y Kobe es un gran puerto, situado a la entrada del mar interior y abierto para todos los buques del mundo.

[Pierre Loti; Japonerías de Otoño, 1889]

\section{Introducción: las islas y sus imaginarios}

Este artículo reflexiona sobre la construcción del imaginario del "Lejano Oriente"; especialmente sobre el Japón evocado en la obra: Sensaciones de Japón y de la China, de 1915, escrita por el salvadoreño Arturo Ambrogi. Este libro hace énfasis en ciertas formaciones y deformaciones de imágenes sobre el desconocido "Japón" de principio del siglo XX, que había heredado un imaginario, un japonismo creciente en la Europa de finales del XIX. El salvadoreño enfocará su particular visión a creaciones que circundan lo exótico y lo romántico; especifica algunos contenidos extraños o foráneos a la visualización del Japón moderno, así como discurre sobre ciertas problemáticas generadas en torno a la industria del turismo en expansión desde principios del siglo XX.

El "Lejano Oriente" es un concepto que desde los escritos de Marco Polo indicaba una frontera, no sólo física sino especialmente imaginaria. Con el desarrollo de las tecnologías del transporte, estas fronteras del imaginario colectivo se fueron acercando hasta hacerse tangibles (hoy, a pocas horas de vuelo comercial). A finales del siglo XIX se abre una de estas últimas fronteras del "Lejano Oriente": Japón. Si bien ubicado al extremo de Asia, la construcción de su imaginario de exotismo, entendimiento y gozo, fue radicalmente distinta a la de otros países asiáticos.

Japón, a diferencia de otras culturas asiáticas, fue adherido a ciertas propuestas estéticas y culturales del eurocentrismo decimonónico, originando el japonismo: necesidad de consumir objetos y signos provenientes de un país que reunía dos condiciones únicas para el imaginario occidental de fin de siglo. La primera: Japón había sido un país prohibido. Visitarlo era inconcebible y 
por ende era un país intangible e inaprehensible; sus narrativas se componían de curiosos conceptos: geishas-artista, samuráis-bushido y harakiri-honor; ideas y valores que chocaron con los sistemas establecidos en la Europa cristiana ${ }^{1}$.

La segunda condición es que Japón es una isla; y una isla fascina la imaginación, estimulándola, modificándola. En la historia de la cartografía las islas aparecían y desaparecían, no estaban fijas, sólo se poseía a veces su perfil y este se movía por el mar. Desde los orígenes de la cultura occidental, las islas han sido fuente de imaginarios, desde los viajes de Odiseo y de los Argonautas, que se prolongan en los de Gulliver y en las búsquedas de Utopía de Tomás Moro y otros pensadores del Renacimiento. Las islas son búsquedas interminables para los osados conquistadores, piratas y aventureros.

En el imaginario del Japón confluyen dos impulsos: la aventura y lo prohibido; tentación de lo desconocido y vértigo del movimiento, del cambio, de lo idílico y lo irreal. Imaginarios que aún se proyectan al inicio del siglo XXI: anualmente Japón atrae un turismo cada vez más selecto, cuyo objetivo es encontrarse con los lugares leídos en crónicas y novelas, recreados y difundidos en la televisión, en el cine, en el video manga y en todos los nuevos símbolos de la "cultura exótica".

Las cualidades de lugar prohibido y paraíso móvil catapultaron el imaginario de Japón como el lugar más lejano del "Lejano Oriente". Paradójicamente, desde que a mediados del siglo XIX Japón abrió sus puertos a los extranjeros, fue conocido y se convirtió en el lugar más cercano del "Lejano Oriente". En las Exposiciones Universales, como la de Barcelona en 1888, el pabellón

1 Sobre el choque ético podemos leer algunas observaciones de Miguel de Unamuno para mostrar un Japón nada exótico que aspiraba los peores males de la Europa, como el patriotismo de principios del siglo XX: "Y como nadie supo ni ha sabido explicarme el estado de alma de aquellos soldados, me he quedado sin saber si admirarlo o compadecerlos. Porque toda esa retórica del patriotismo, el heroísmo, el amor al emperador, el sentimiento del deber o el del honor, son cosas que, en mi desarraigable materialidad de esperanzas de extremo occidental, no puedo sentir, aunque trate de comprenderla" (Unamuno, 1968, Tomo III: 1.119). Unamuno fue un feroz crítico de la moda japonesa que invadía a Occidente y un agudo analista de las reformas religiosas, escribió en un artículo en 1918: "Los japoneses nos tienen a los europeos por caprichosos o fantásticos, por dar tanta importancia como damos a la poesía, a la música, a la religión y a las disquisiciones especulativas. Pues el japonés a consecuencia de su irreligiosidad, es infilosófico. ¡Claro está! ¡Como que toda filosofía ha empezado por ser teología. ¡ha empezado! Y sigue siéndolo. No hay espíritu alguno filosófico, verdaderamente filosófico, sin raíces religiosas, sean de la religión que fueran (...) El patriotismo, a base de vanidad nacional, de un pueblo no religioso y no filosófico, nos parece un grave peligro. Y agréguese el positivismo o pragmatismo en tal pueblo." (Unamuno, 1968, Tomo IX: 1.556).

2 Podemos ver una innumerable cantidad de films con estos elementos exóticos; algunos: The Last Samurai (2003) de Edward Zwick; Lost in Translatio (2003) de Sofia Coppola; Memoirs of a Geisha (2005) de Rob Marshall; The fast and the furious. Tokyo Drift (2006) de Justin Lin. 
japonés era uno de los más visitados y sorprendentes de los que se instalaron; los europeos tuvieron así un contacto directo con las artes pictóricas (ukiyo-e), que estimularon a varios artistas del momento y renovaron ciertas visiones estéticas para privilegiar lo exótico sobre lo conocido (Almazán, 2006). La masiva visita al pabellón japonés de la Exposición Universal de París en 1900, lleno de geishas que recibían al público fascinado con aquel particular arte donde resaltaban los dibujos de gran precisión de líneas, cerámicas inauditas que simulaban cascarones de huevos y tejidos de seda brillante en combinaciones jamás soñadas; allí se encontraban con personajes como Sadda Yacco, una mujer que parecía salir de un grabado para materializar un sueño, y que entre telones inspiró a Puccini la Madame Butterfly³.

Las fronteras imaginarias de Japón se constituyeron con estos dos rasgos: isla móvil y prohibida, para luego transformase en lugar "próximo": posible, estable, conocido, al alcance de la mano. Este cambio animado por las Exposiciones Universales se materializa en las búsquedas estéticas de las artes de principios del siglo XX; y se han consolidado en el presente en los imaginarios occidentales sobre los usos de la tecnología, los Made in Japan y la popularización del anime y el manga japonés.

A lo largo de la historia de las civilizaciones, Asia era un lugar de intercambios mercantiles que ya desde el tiempo de Marco Polo había sido descrito y cartografiado, pero que desde finales del siglo XIX se transforma en territorios de colonias y protectorados. Quizás sólo Japón se presentó desde su inicio como unidad económica con estructura política, como un país que se abría a Occidente y con el que se posibilitaba el comercio entre países. Así, no

3 En el libro La mujer japonesa, realidad y mito (Barlés y Almazán, 2008) destacan varios artículos sobre la presencia de Sada Yacco en Europa, entre ellos: "Madame Butterfly y sus fuentes: la creación del mito", de Luisa Gutiérrez Macho, muestra los entretelones en que se confeccionó Madame Butterfly, Puccini entrevistó a Sada para recrear el Japonismo que se difundirá a principios del siglo XX; en el mismo tono, "Admiración o condescendencia: Sadayakko en Barcelona", escrito por Minoru Shiraishi y Jordi Mas López, relata el error occidental de considerar a Sadda Yacco como representante de la mujer japonesa: "Parece que la imagen de Sadayakko causó un gran impacto en Europa, puesto que era como salida de una imagen de ukiyo-e. En Japón, en cambio, no se la consideraba una mujer con las facciones demasiado japonesas (...) La media de la altura de esta época era de 1,54 m., pero ella medía 1,57, es decir, era tres centímetros más alta que la media y en consecuencia destacaba entre las otras chicas. Tenía buena figura, piernas largas y caderas altas. En general los japoneses no tienen los párpados del ojo doble como los occidentales, pero Sadayyako tenía el párpado del ojo derecho doble, su nariz era recta y más marcada que la de una japonesa normal y su piel era blanca como la nieve. Estos dos últimos factores, piel blanca y nariz marcada, eran los rasgos fundamentales de lo que significaba ser bella en Japón. Las piernas largas, la piel blanca y la nariz marcada son características de las occidentales (Barlés y Almazán, 2008: 868). 
fue conquistado por las ansias expansionistas de los imperios británico o francés, ni desmarcado como colonia, inaprehensible para el imaginario colonial de la época. Japón entra al siglo XX como frontera lejana, cultura exótica no colonizada, unidad política, religiosa y cultural propia y en apariencia no contagiada, con la que es posible el intercambio comercial y científico; elementos que se unirán en el imaginario de los japoneses mismos para pensar a Japón como un país occidental en el "Lejano Oriente".

Durante siglos, las políticas de control prohibieron en Japón todo lo occidental; al abrir los puertos, cientos de productos y artefactos provenientes de Europa se transformaron en tentación de consumo, produciendo un descontrol de identidad, ideas e imaginarios. Consumir occidente mostraba el camino de la industrialización y su prole: el imperio. Los productos poseían valor agregado para los japoneses: la posibilidad de superar sus condiciones feudales y transformarse en un país "superior". En Japón se asentó un imaginario sostenido por discursos darwinianos, cientificistas, industrialistas, pragmatistas, en otras palabras: del "progreso" que aliviaría el hambre, la pobreza, las enfermedades; pero que por otra parte comenzó a afectar el paisaje y la sociedad japonesa, como lo visualizó a finales del siglo XIX Lafcadio Hearn en Japón un intento de interpretación:

El espíritu popular no es tan ignorante como para no darse cuenta de que la primera causa de la pobreza es la instrucción de los métodos industriales occidentales y no resulta agradable reflejar lo que tal agitación podría significar. De momento no se ha hecho nada para mejorar la situación de los trabajadores más desfavorecidos, que ahora ascienden a más de medio millón. (Hearn, 2009: 224).

Cuando las fronteras están juntas, cuando lo que hay que hacer es dar un paso, las fronteras son peligrosas, se llenan de enemigos, y las usamos para intercambiar nuestros excesos o para satisfacer nuestras necesidades. Una frontera lejana estimula la utopía, los cambios, las reflexiones; no es lo mismo pensar un imaginario de la frontera entre países vecinos, por ejemplo: México con Guatemala o México con EE.UU., pues sus narraciones no alcanzan a conformarse en una línea de horizonte definida, ésta se quiebra en clasificaciones, separaciones, ansias de dominar al otro o de protegerse de los otros allende la frontera. 
Las fronteras asiáticas, desde América Latina, se transforman en horizonte: frontera horizontal de partidas y llegadas que han de ser contadas y expuestas en narraciones. Son representadas en dos estilos: el primero, el encanto del horizonte, las "crónicas de encanto" mostrarán una relación entre lo imaginado y lo real que se mantendrá en los meandros de lo exótico, lo particular y lo fascinante, mostrando el horizonte asiático y especialmente Japón como un lugar de saber y de belleza, como hizo el guatemalteco Enrique Gómez Carrillo, cuando a principios del siglo XX recorrió un Asia vedada para la mayoría de los latinoamericanos, registrando en sus crónicas las inigualables bellezas que vio.

El segundo estilo presenta un horizonte que se transforma en lugar tangible y reconocible; y sobre él surge un desencanto. En las "crónicas de desencanto" lo lejano se muestra cercano, nos recuerda el propio vecindario, nuestra calle, nuestro barrio, los elementos familiares para dominar, separar y clasificar a los otros. Lo exótico se transforma en revelación común, tan cotidiana y propia que el cronista considera vulgar. En esta segunda vía narrativa lo exótico se transforma en lugar común y banal. Esta es la mirada que nos presentan las crónicas del salvadoreño Arturo Ambrogi.

Traspasar los horizontes asiáticos a principios del siglo XX, especialmente el japonés, fue para los cronistas latinoamericanos una experiencia que quisieron transmitir a sus lectores; algunos preservando el imaginario exótico: Gómez Carrillo, Rebolledo, Tablada; que podemos identificar como "cronistas de encanto" (con la salvedad de Gómez Carrillo que a veces mostraba sus dudas y desasosiegos sobre su encantadora Asia). En cambio, Ambrogi fue uno de los cronistas latinoamericanos cuyas perspectivas apuntaban a desmontar el encanto; así como en cierto momento hicieron Pierre Loti o Rudyard Kipling en sus escritos sobre Japón.

Ambrogi expone una mirada menos exótica y más pintoresca: caminar entre tiendas para satisfacer el consumismo del turista, ver a los asiáticos vestidos a la occidental, como cualquier persona en una calle que disfruta de un paseo entre las galerías. Ambrogi se aleja de las flores del cerezo y de las geishas, y nos presenta la tragedia y la comedia del exotismo, de los horizontes impenetrables pero vecinos, del declive de los imaginarios románticos, simbolistas y modernistas entre personas insolentes, granujas y torpes. 
Nuestra idea es mostrar en la obra de Ambrogi: Sensaciones del Japón y de la China, estas narraciones más pintorescas que exóticas, más vulgares que maravillosas, más turísticas que insospechadas; precisamente, descifrar el estilo de las "crónicas de desencanto" en contraste con las "crónicas de encanto" que escribieron otros cronistas de América Latina que tuvieron la oportunidad de viajar, a principios del siglo XX, a Japón.

\section{Encuentro de dos modernistas en París hablando sobre Japón}

El Modernismo fue el movimiento literario que transformó los estilos y los imaginarios de los poetas latinoamericanos a finales del siglo XIX. Los primeros modernistas expresaron en sus imágenes su aspiración a un esteticismo extremo, a la búsqueda de la forma y la belleza; ideal que los distanciaba de todo realismo positivista, y los avocaba al viaje, a la invención y a la creación de nuevos códigos poéticos: lo exótico, lo lejano, los horizontes. Miradas de encanto frente a los desencantos de la modernidad y la industrialización positivista en América Latina.

En su libro Orientalismo en la modernidad hispanoamericana, Aracelis Trejo muestra los diversos caminos que tomaron los escritores latinoamericanos para representar los imaginarios de Oriente y en especial de Japón -la isla, lo prohibido, la tentación-. El japonismo abrazado por los poetas latinoamericanos viene desde las fuentes parnasianas y simbolistas de la poesía francesa del XIX que los influyeron. Théophile Gautier y los hermanos Goncourt iniciaron el japonismo en París, cuando buscaron aprehender la "novedad" y la fascinación del mundo revelado en las Exposiciones Universales, donde atraídos por la variedad de objetos, imágenes, libros y porcelanas, dibujos, perfumes y leyendas que apuntaban hacia Japón, tierra de ensueño, paraíso inexplorado, pasado mítico y legendario de los grandes samurái y las pequeñas geishas. Los modernistas hispanoamericanos, así como los poetas parnasianos, simbolistas, prerrafaelistas, decadentistas y todos los movimientos europeos de finales del siglo XIX y principios del siglo XX, encontraron en Japón un lugar para imaginar, escudriñar y amar.

Es 1913 y en París, la ciudad luz, que siempre fue un constante punto de encuentro de los modernistas latinoamericanos. En una de las Crónicas Marchitas (1962) el salvadoreño Arturo Ambrogi relata la visita que hiciera al poeta guatemalteco Gómez Carrillo en su casa. Lo halló en medio de centenares de libros y periódicos y pronto a realizar un viaje a España para publicar La 
sonrisa de la esfinge, libro en que reunía sus crónicas de viaje por Egipto. Ambrogi, que venía de regreso de su viaje por Oriente, comienza a rememorar su estancia en "el Cairo europeo" de largas calles y árboles, "construcciones vulgares que recuerda Shan-Hai, Hong Kong, Singapur...". Luego de oírlo, Gómez Carrillo le regala unos libros:

-Aquí tienes lo último que he publicado. Rosas de penitencia y El Japón heroico y galante. ¿No los conoces? ¿No? Pues llévatelos. Al del Japón (que no es más que una refundición de mis dos anteriores libros sobre aquel país) le hallarás todo su sabor, puesto que, precisamente vienes de allá. Léelo, y dime con franqueza, cómo encuentras "mi Japón”. (Todo escritor que va al Japón, y escribe sus impresiones, se cree con el derecho a tener 'su Japón').” (Ambrogi, 1962: 68-69).

A partir de este encuentro, Ambrogi reflexiona y genera cierta crítica a las visiones de "Japón" que los cronistas evocan, pues considera que estas son tergiversaciones de la realidad. Ambrogi insinúa que los cronistas no comentan lo que perciben, lo que les acontece, que soslayan la vulgaridad que los rodea, solo para complacer a un público -así se lo expresa a Gómez Carrillo-: el comercio tergiversa las experiencias estéticas y las prepotencias y los abusos de los turistas nublan los imaginarios; Gómez Carrillo responde: “¿Qué quiere? Así son” (Ambrogi, 1962: 67).

Así son las personas que van a Japón: tienen su propio Japón, el que quieren encontrar y que derivan de las crónicas, fotos y escritos vistos y leídos; productos culturales que le permiten imaginar un lugar fuera de lo común, un más allá posible, un paraíso en la tierra. El público desea ese imaginario de lo exótico que el prolífico autor guatemalteco proveyó a través de sus crónicas: De Marsella a Tokio y El alma japonesa; que posteriormente compila en El Japón heroico y galante ${ }^{4}$. Esta obra, en las primeras décadas del siglo XXI, se ha convertido en un curioso Best Seller, más de cinco ediciones, y una publicación académica con extensa introducción crítica y más de trecientos pies de páginas, realizada por Ricardo De La Fuente Ballesteros en la Universidad de Valladolid.

4 Aclaramos que El Japón heroico y galante es una selección de sus libros anteriores (De Marsella a Tokio y El alma japonesa). En esta selección se observa el énfasis en el encanto; pero en los dos volúmenes hay otros capítulos que caracterizan cierta banalización, crueldad, vulgaridad y estupefacción del Japón; en esa medida hay más equilibro que "su” Japón heroico y galante. 
El Japón beroico y galante de Gómez Carrillo, “su Japón”, es una “crónica de encanto", excita la imaginación de sus lectores a visualizar un Japón exclusivo, exótico, inaudito, improbable. Anoto que aunque hay algunos párrafos "críticos", estos pasan como puntuales. ¿Será por esto que su libro ha logrado tal éxito? Porque, en cambio, Sensaciones de Japón y China de Ambrogi no ha impactado igualmente al público, y por eso su edición original de 1915 no ha tenido reimpresiones.

Esta conversación sobre Japón entre dos intelectuales centroamericanos está llena de resonancias. Cada uno describió su horizonte con sus ritmos, sus admiraciones y decepciones. Gómez Carrillo muestra ciertas curiosidades de Japón, alejadas de lo cotidiano europeo, como el seppuku o la ética del busbido o la risa eterna del japonés; y así construye la mayoría de los relatos. Sólo un artículo de su libro -"La miseria"- muestra un aspecto de ese Japón decadente que Arturo Ambrogi, en cambio, marcará constantemente. Para Ambrogi, "su Japón" es más parecido a la Europa moderna que al país de los ukiyo-e, que tanta fama dieron a Hokusai, Utamaru, Hiroshigue, así como a los hermanos Goncourt y a José Juan Tablada; alejado del bushido y del seppuku, un Japón que convertido en destino turístico puede decepcionar. La pérdida de la frontera y de lo lejano aparece en ambos autores; pero mientras Ambrogi la describe con cierta tristeza, Gómez Carrillo parece disfrazarla, como advierte en su libro De Marsella a Tokio, sobre su llegada a Yokohama:

\begin{abstract}
-Francamente ¿qué le parece a usted? Todos mis compañeros de viaje me hacen, al cabo de dos horas de paseo por las calles de Yokohama, la misma pregunta. Y por el tono y por el rostro, se comprende desde luego que están desilusionados. Esto que vemos, no es lo que ellos querían ver. Los libros les habían hablado de progreso, de europeización, de modernidad. No importa. Un misterioso instinto decíales que, a pesar de todo el progreso, las antiguas costumbres, los antiguos trajes y las antiguas calles, tenían que subsistir. (Gómez Carrillo, 1907: 139).
\end{abstract}

Ambrogi no va a buscar en Japón lo que debía existir, muestra precisamente lo que existe, lo que experimenta y construye desde su mirada del desencanto. Constantemente el autor salvadoreño explica los desarrollos industriales 
que aúpan la modernidad japonesa, pero que maltratan al pueblo japonés, obligándolo a vivir su exotismo dentro de sus propias fronteras, socavando así la identidad del pueblo "puro" que los extranjeros desean apreciar. Esto trajo a Japón una interesante remarcación de fronteras, ya no con un país de al lado, ya no con un horizonte lejano, sino dentro de sus propios límites; fronteras que Ambrogi marca como lugares esnobistas. Hay antipatía y asco en su transitar por Ginza en Tokio de finales de la primera década del siglo $\mathrm{XX}$, cruzando una frontera invertida dentro del territorio japonés:

\begin{abstract}
Ahora es una "kinumono", una tienda de seda, exhibiendo "kimonos y "yukatas” para la exportación. ¡Uf! Paso de largo tapándome las narices. La misma impresión repulsiva experimento ante una agencia de automóviles, en cuyo anchuroso garaje acristalado, se enfilan los antipáticos armatostes. Una farmacia, con sus drogas en tarros de loza vidriada, la etiqueta azul en la panza, alineados en los estantes barnizados, y tras el mostrador, un dependiente, prepara en un mortero algún ungüento. ¡Un restaurant a la europea, con sus cristales recubiertos de visillos de encaje". Es el "Viena", como si se dijera, el "Café de París" de Tokio. Un grupo de elegantes empuja las vidrieras, monografiadas de oro, y penetra. Y al batir de las hojas, salta a la calle el eco de una orquesta, que en un compás de marcha funeral ataca una fantasía del "Fausto". En el piso, en el alféizar de las ventanas de guillotina, hay tiestos con flores y se divisa el fleco de una cortina de damasco rojo, y el remate dorado de un cuadro. El cocinero del "Viena" ha sido traído de Londres, y su "menú" esta redactado en francés y en inglés, y no en japonés. Estas son las cosas que a mí me ponen nervioso. Luego llegamos a una tiendecita de flores: un verdadero oasis en medio de toda esta aridez." (Ambrogi, 1915: 89).
\end{abstract}

El esnobismo marca una línea entre el Japón que busca el turista y el Japón que busca el modernista, y en el cruce de estos límites imaginarios se construye la narración del salvadoreño. Ambrogi ve el exotismo japonés del mismo modo como los nipones encuentran exótico un menú en francés en Ginza, algo irreal pero aprehensible. Podemos recorrer las páginas de Sensaciones de Japón y de China y apreciar sus reflexiones acerca de las personas que en Japón han compuesto “su Japón”, casos de Hearn, Kipling, Gómez Carrillo, Tablada, Rebolledo. Ambrogi llega a "su Japón”, el de los empresarios, las 
personas de negocios y la burguesía que busca el placer de las aventuras lejos de cualquier éxtasis estético o respeto cultural, y que para el salvadoreño son la mayoría del contingente de personas que viajan a Japón.

Gómez Carrillo mantenía un Oriente exótico en sus escritos para sus ávidos lectores de los periódicos La Nación de Argentina, y El Liberal de España, quienes acarreaban sus gastos en Japón, y para los cuales debía escribir reportajes de un Japón triunfante de la guerra Ruso-japonesa; así como llenar de mitos e historias, páginas de reportajes barnizados con descripciones de los ukiyo-e. Ambrogi, en cambio, era un observador de paso, y sus crónicas se publicaron en El Salvador, merced a sus contactos políticos, la edición se dirigía a un público diferente al de la gran prensa, así Ambrogi se sentía en libertad de mostrar las virtudes y los vicios de los pueblos, para explicar ciertas condiciones humanas.

La diversa finalidad de sus escritos y los divergentes intereses de los públicos de los dos autores, pueden explicar que sobre el Japón uno compusiera "crónicas de encanto", y el otro "crónicas de desencanto".

\title{
Crónicas de desencanto
}

Japón configura un emblema de experiencias estéticas o por lo menos así lo describen varios escritores y aventureros que arribaron a Japón a principios del siglo XX, como Lafcadio Hearn.

\begin{abstract}
¿Cómo no sentirse seducido por una civilización en la que toda relación parece estar regida por el altruismo, cada acción dirigida por el deber y cada objeto moldeado por el arte? Uno no puede dejar de deleitarse ante todo ello o de indignarse cuando alguien la califica de "pagana". Y según el de cada uno, esta buena gente será capaz, sin esfuerzo aparente, de hacerte feliz. La mera sensación del entorno es ya de una plácida felicidad: como en un sueño la gente te saluda del modo que deseas, te dice lo que quieres oír y hace por ti lo que necesitas; se mueven silenciosamente por un espacio de perfecta tranquilidad bañados por una luz vaporosa. (Hearn, 2009, 21).
\end{abstract}

Pero estas experiencias estéticas se redujeron con el tiempo a meras descripciones o análisis de una cultura particular, como cualquier otro acercamiento de mirada sociológica o antropológica. Japón, a diferencia de otras 
culturas asiáticas que en el siglo XIX fueron eliminadas para que en sus espacios se desarrollaran meros campos de cultivos o de explotación de materias primas, como ocurrió con la fundación de colonias en China (Shanghái, Macao y Hong Kong), India, Malasia, Filipinas, Australia e Indonesia. Por ejemplo, en la isla de Guinea la colonización de ingleses, franceses, holandeses y alemanes, redujo una de las diversidades lingüísticas más amplias de la tierra. Cientos de culturas asiáticas fueron perdiendo sus lineamentos, cosmovisiones, lenguajes, porque no se pudieron presentar como países sino como fragmentos aprovechables, que desde la época de Marco Polo o desde el siglo XV se transformaron en colonias y perdieron su exotismo cultural por el exotismo de sus productos.

Desde Asia venían a Europa sedas, especias, porcelanas, artilugios, todo fabricado o cosechado por culis o peones dirigidos por una aristocracia "culta" y una clase burguesa en crecimiento y expansión. Antes de la Segunda Guerra Mundial, Shanghái era una de las ciudades más pobladas del mundo, más de 70.000 extranjeros habitaban en ella. Los elementos culturales chinos (ritos, mitos, literatura y música) se enfocaban en el ámbito privado, mientras en lo público las mercancías y negocios se exhibían y asimilaban. Condiciones similares padecieron el resto de las demás colonias.

Asia era un continente vasto dividido por intereses económicos y políticos, pero no Japón, que siempre se describió como un país, como una unidad cultural, con una manera particular de ser y hacer las cosas. Japón se ofreció como el lugar "exótico" y "exclusivo" de Asia, donde las mujeres danzaban por la calle en kimono juntos a hombres fieros que eran capaces de un suicidio ritual con espadas nunca vistas; las crónicas hablaban de un pueblo capaz de crear artilugios y bellezas nunca apreciadas, y de promover la contemplación de una naturaleza sin igual. En este imaginario, Japón se abrió al comercio y puso a la disposición Occidente artefactos de lujo, placer o lúdicos. Japón obtuvo un éxito inusitado en su apertura al mundo como un país del "Lejano Oriente", pero accesible y cercano, un país que se podía consumir en los viajes o a través de sus particulares objetos: cerámica, ukiyo-e, kimonos, biombos e inclusive fotografías. En Europa y EE.UU. el fetichismo y la mercantilización de las mercancías japonesas las fue despojando de sus sentidos y significados. Pero como el comercio es 
bidireccional, los artefactos occidentales también fueron despojados de sus sentidos y significados en Japón; así, fueron muchas veces redimensionados, perfeccionados y convertidos en fetiches, como los lentes redondos que llegaron a ser un bien nacional, según comenta Gómez Carrillo.

Ya había yo notado en Yokohama y en Kobe que apenas hay japonés sin lentes. Los soldados, los conductores de tranvía, los agentes de policía, los horteras, los trabajadores de las fábricas, todo el mundo los usa. Son objetos de necesidad nacional. Y así, es de contemplar la facha extraña de estas multitudes que pasan bajo los amplios paraguas de papel engomado, en equilibrio sobre sus altas sandalias de madera, con los kimonos arremangados hasta la cintura y los lentes puestos - los redondos, los enormes lentes éstos, que parecen copiados en las caricaturas alemanas-. Me acuerdo de haber visto, hace mucho tiempo, en una pantomima parisiense, a un doctor del Paraguay desnudo, pero con quevedos de oro, y aquella imagen me obsesiona desde hace días como un símbolo de esta gente. (Gómez Carrillo, 2011, 67).

Al Japón se lo consume a través de imágenes, de grabados que circulan masivamente por revistas ilustradas y a través de la mundialización del mercado de sus artículos suntuarios: artículos de porcelana, finos abanicos, lacados. Para las élites culturales occidentales, poseer un objeto japonés implicaba buen gusto y refinamiento. Japón, en las primeras décadas del siglo XX, era también el único país no occidental que se estaba industrializando y modernizando exitosamente.

Se podría pensar también que su proceso de modernización iba a la par de su ruta militarista; sus éxitos en el campo militar fascinaron a personas que comenzaron a buscar a Japón en los mapas. Sus triunfos y victorias contra Rusia en 1905, atrajeron a un contingente de periodistas de todas partes del mundo (incluyendo a Gómez Carrillo) para explicar al mundo qué era Japón: un país que pretende derrotar a otro país tiene puesto en la sociedad de naciones y puede tratar con otros países e Imperios con su identidad de nación y no con la resignación de ser protectorado o colonia. La rápida y entusiasta industrialización y estabilidad económica, ligada a los éxitos militares de Japón, comenzó a estimular un flujo de capitales que trajo a empresas de todos los sectores, especialmente uno que comenzaba: el turismo. 
Los relatos de Gómez Carrillo, así como algunos de Ambrogi, eluden varias veces esta dimensión "capitalista" del turismo para imprimir sensaciones de cierta belleza y exclusividad sin opacarlas con lo cotidiano y lo vulgar. Si bien Gómez Carrillo alguna vez comenta cómo la industrialización afea la ciudad, estas líneas desaparecen para mostrar al exótico Japón. Más perspicaz y meditabundo se presenta Ambrogi, que describe los resultados de la industrialización como un reflejo de una modernidad que imprime a sus objetos comerciales un "valor" que no es estéticamente cuantificable; nos describe la belleza de los productos japoneses, pero sin dejar de mencionar a los consumidores finales de tal belleza: los turistas que vienen a Japón, no para hallar un lugar exótico, un resumen de beldad, como lo representan varios escritores, sino para ver y certificar lo visto y en ese proceso adquirir bienes de consumo y recuerdos, sin ampliar sus experiencias estéticas, sin obtener un horizonte cultural que los vuelva más humanos. El turista viene a ver "su Japón", de eso se lamenta Ambrogi, que observa por las calles de Tokio, Shanghái y Saigón, un turismo de pequeños burgueses torpes y vulgares o de aristócratas prepotentes. Así podemos leer "En la tienda de Curios", una descripción de su visita a una tienda donde, lleno de admiración por el arte japonés comienza a detallar los objetos, con una carga de decepción por los destinatarios: los turistas.

Hemos ido más lejos. En sus largas cajas yacen, enrolladas, "kakemonos" y "makemonos". Los hay de simple tela; los hay a la vez de seda riquísima. Los hay, que llevan, al margen, las patas de mosca de Hokusai, y que valen una montaña de "yenes". Esos, sólo los acaudalados ingleses, o los saladores de cerdos de Chicago pueden llevárselo. Desenrollo dos, tres Paisajes. El Fusiyama y su perfecto nevado, en todo fondo, sin variaciones. Ramas de cerezo florida. "Musumés" recogiditas bajo sus frondosas "amagasas". Rincones del Sumida-gawa, en que imperan los clarobscuros clásicos, y en medio de los cuales se desliza misterioso "fune", apenas alumbrado por una linterna roja. (Ambrogi, 1915: 11).

La particular descripción del cronista resalta cierta belleza en los objetos, pero deja afluir también su sarcasmo ante sus posibles compradores: "los saladores de Chicago". Gómez Carrillo, Rebolledo o Tablada centran su narrativa en meros encuentros con la belleza japonesa, a la vez que se rodean de perso- 
nas con cierto nivel cultural y experiencias estéticas, por ejemplo, Gómez Carrillo intercambia sus opiniones del Japón con profesores o embajadores que le acompañan en sus andanzas; también Efrén Rebolledo dedica su Nikko "Al Barón Silvestre de Marchi della Costa y a la baronesa de Marchi della Costa, en recuerdo del verano venturoso pasado en las montañas de Nikko, bajo el continuo encanto de los templos de laca roja de los cedros, de las cigarras y de las cascadas". La mayoría de los cronistas que visitaban a Japón a principios del siglo XX se rodeaban de gente "culta", de apreciadores de la belleza.

En cambio, Ambrogi escribe lejos de nobles, diplomáticos, profesores o individuos cultos; el salvadoreño, prefiere ir solitario o esporádicamente acompañado por algún negociante como Kraken, un alemán centrado en su vicio del tabaco que apenas percibe la belleza, o por personas humildes como Nobu, su kuruma-ya, quien conduce un carro tirado por sus propias fuerzas; el escritor descubre que Nobu nunca había ido a Nikko, y cuenta cómo se conmueve frente a la belleza que le es propia pero ajena. Ambrogi se relaciona con personas sencillas, trata de comunicarse y comprenderlas: una visita al parque Hibiya solo tiene por objeto observar a la gente común y corriente en sus actividades cotidianas. Mirada distinta a la del turista que es un conocedor prepotente, autosuficiente, que no se deja subyugar por los elementos sublimes que la naturaleza da.

Yo contemplaba aquello con ojos de turista, más o menos documentado; con pasión de artista tal vez, y por aditamento, con un poco de vanidad de cronista que piensa en que mañana podrá hablar de algo que no a todos les es concedido. En el sentimiento admirativo de Nobu, por sobre su ingenuo amor por la Naturaleza innato en todo japonés de elevada o baja posición, flotaba un intenso espíritu de misticismo, un soplo de misterio. Para Nobu aquel viaje a Nikko, acompañando a un turista generoso, el cual hablaba en una lengua fabulosa, era como una peregrinación al Arca Santa de las creencias ancestrales. (Ambrogi, 1915: 70).

Algunas decepciones del cronista contrastan con los imaginarios del Japón exótico, único, dador de belleza. Comienza a percibir la vulgaridad occidental que describe con cierta precisión, calle tras calle, luego de visitar cada mercado, luego de salir solo del hotel en Tokio, Nagoya, Kioto, Hong Kong, Shanghái o Saigón: descubre los comercios, las miserias y los 
abandonos. Lo exótico se desvanece para mostrar los mercados abiertos, lugares para realizar transacciones económicas y obtener productos. Nadie se cuestiona ante la ceremonia del té o ante un templo, solo cuenta la vanidad de hablar de lo que no es dado a todos, este ir a ver lugares específicos y no detallar ni meditar sobre ello, se aúna al ímpetu comercial de las calles y transforma el exótico Japón en un fin turístico de compras, quizás el primero en Asia.

A cada paso se cierra el círculo de posibilidades para conocer profundamente la cultura japonesa sin sus edulcorados productos para el turismo; la esencia del Japón de Gómez Carrillo conlleva una trampa que el salvadoreño trata de evitar. Ambrogi duda, reniega y se asombra de los cambios que se producen en Japón, como también apuntó Loti con su estilo irónico, o Hearn con la preocupación propia de un padre protector. Ambrogi posee la misma estupefacción de Walter Benjamin (Libro de los pasajes) ante un París en constante metamorfosis, que nace de los nuevos materiales, el hierro y el cristal, que se llena de tiendas y galerías de prestigiosos nombres y también de tiendas más humildes; mutatis mutandis, Ambrogi recrea su perplejidad cuando compara a Osaka con Manchester, o a Kioto con las galerías de París, o a las personas esperando las ofertas frente a tiendas de Tokio, como en cualquier tienda de Londres; en todas partes el cielo se llena de cables eléctricos y de telegrafía.

En su rostro afeminado, máscaras de tristeza y de melancolía, no resplandece ni un breve instante, la sonrisa plácida y cortés del "kuruma-ya"; ni tan siquiera su fondo de odio se refleja en una fugaz mueca de rebeldía, como la misma hermosa pasión en los labios exangües y el brillo de los ojos de ave de rapiña del "coolie". Es la del anamita la expresión de un ser embrutecido por la crueldad de sus conquistadores, amedrentado y sumiso. Sufre, callado, con todo su cuerpo. Es un mártir. El oficial colonial, ebrio, grosero, le aporrea, sin motivo, como a un perro. Los soldados holgazanes, les dan peor trato que a las bestias, y les obligan, por la fuerza a arrastrarles, escatimándose el mísero pago. El anamita tiembla ante el colonizador, odioso, antipático; el más cruel más insolente, que el inglés en la India y Egipto” (Ambrogi, 1915: 191). 
Los kuruma-ya, rickshaw, o pouse-pouse, mueven con su cuerpo aquellos carros y se transforman en guías turísticos llevando a los extranjeros por las intrincadas calles de las ciudades asiáticas colonizadas, y que aún podemos experimentar hoy en plena Nueva Delhi si vamos a un lugar como Chandni Chowk; o En Japón, en Kioto o Matsuyama. Las diferencias entre la experiencia en India y Japón, se remontan a su origen: los japoneses transportaban a los extranjeros desde sus hoteles hasta las tiendas bajo un sistema de contrato o de transacción económica en que había un trato de respeto. Muchos kuruma-ya tenían contratos establecidos con los hoteles, como comenta Ambrogi de Nobu, por lo que ellos constituían un grupo especializado en atender a los turistas en pos del exotismo; mientras los rickshaw de China y Conchinchina hacían similares funciones de guías, pero bajo una relación de servidumbre entre amo y esclavo, dominador y dominado.

Los guías presentaban el Japón que el turista quería ver, así se lee en las entrelíneas del curioso relato de Ambrogi en una "hiketechaya" a donde fue llevado a comprar y consumir té, sueños, imaginarios exóticos. En la casa de té, el cronista habla de la belleza de la mujer japonesa, de su disposición, de sus risas, de sus manos, detallando una beldad sólo contemplable en Japón. Similar anécdota narró Kipling; lo curioso es que Ambrogi nos habla de 引手茶屋【ひきてぢやや】 una casa de té que en realidad era un lugar para citarse con prostitutas. Podríamos deducir que los kurumaya llevaban a los clientes solitarios a conocer ciertos placeres exóticos. Quizás ni Kipling ni Ambrogi entendieron la astucia de sus kuruma-ya y optaron por narrar una experiencia "formalmente" exótica. Casi todos los cronistas que visitaron Japón fueron a Yoshiwara, el gran centro prostibular de Tokio, lo que indica que el turismo sexual siempre ha sido una de las banderas del comercio de lo exótico. Ambrongi comienza su libro saliendo de Yoshiwara: "Regresando de Yoshiwara, feérico e inolvidable, con la visión de sus esplendores todavía en la retina, y con las sutiles emanaciones de sus iris, sus glycinas y sus azaleas, todavía flotando en mi cerebro" (Ambrogi, 1915, 19). No profundiza ni describe sus experiencias eróticas, quizás no es el caso de todos los cronistas, pero nos confiesa que el kuruma-ya es su guía, su Virgilio por Yoshiwara. En El alma japonesa, Gómez Carrillo dedica el último capítulo a la belleza de Yoshiwara, una na- 
rración de bajorrelieve del mundo erótico japonés, adornada con historias y relatos románticos como la de Gompachi y Komurasaki o recreando los ukiyo-e de Utamru. Ambrogi conoce estos elementos, pero curiosamente solo los menciona como algo inolvidable. Es Nobu, el guía, que con cansada sonrisa observa la satisfacción de su cliente y espera su paga.

Viajar a este país es costoso, implica un estatus, un capital burgués y son estas personas las que mantienen el imaginario de un Japón, no como un país sino como un "lugar" exótico. Estos viajeros, estos cronistas como Gómez Carrillo y como Ambrogi, fueron alimentados por el japonismo de la época y a su manera lo mantuvieron a través de sus descripciones, pero quizás a diferencia de muchos de los que fueron a Japón, China y Conchinchina, Ambrogi recalcó los problemas en hacer turismo en "colonias", explica los primeros guías turísticos y especialmente Japón como un país turístico, como el Imperio que quiere llegar a ser, y no como "lugar" de un imaginario exótico que popularmente se ha sostenido y que aún podemos hallar en libros, medios de comunicación y cine.

Puede pensarse que el modernismo, el simbolismo, los prerrafaelistas y todos los movimientos intelectuales y culturales del siglo XIX lograron una "evolución" con Japón, porque al abrir sus puertas a la modernidad, abrieron sus puertas a sus manufacturas, replantearon sus consumos y el negocio del turismo, creando fuentes de trabajo. Con el auge de la burguesía comienza la era del turismo y de las compras exóticas, es por eso que el turismo se profesionaliza desde mediados del siglo XIX para una clase adinerada, por medio de compañías como Thomas and Son y America Express Company. Se empiezan a preparar barcos con fines turísticos y viajes especiales, como la vuelta al mundo que se realizó en 1872 y duró 222 días e inspiró la obra de Julio Verne: La vuelta al mundo en ochenta días. Sabemos que cuando Ambrogi visitó a Gómez Carrillo había hecho sus viajes al "Lejano Oriente" en los barcos de Thomas and Son que tenían paradas "obligatorias" en algunos lugares como El Cairo, para apreciar las pirámides y comprar artilugios y piezas con jeroglíficos. Ambrogi muestra cierta aprehensión hacia la vulgarización que destila del comercio; pero los prejuicios comerciales impuestos por el mercado a lo exótico, permitieron vivir la experiencia de los viajes, de ahondar los imaginarios, del intercambio de ideas, pensamientos y estéticas, creando así "su Japón”. 


\section{Conclusiones: Coda}

Entre los viajeros y cronistas se desarrollan dos tipos de narrativas; una que busca hallar lo que en los imaginarios derivados por lecturas previas han concebido y confeccionado como el "lugar exótico", que representan a través de "crónicas de encanto", donde lo que se aprecia es lo que se ha previsto. Otra, cuando el imaginario no encaja en el lugar y el cronista descubre un país, una economía, una política, una sociedad semejante a la suya, podemos hablar de "crónicas de desencanto"; esta visión fue la que desarrolló Ambrogi en sus escritos.

Ambrogi desembarca en un Oriente que progresivamente va perdiendo su exotismo, Japón se desvanece como una isla imprecisa para mostrarse como un país con ansias de Imperio. Japón pierde el encanto de lo prohibido y de lo misterioso para trasformase a los ojos de Ambrogi en un país de lo vulgar, del esnobismo, del turismo para diversos fines incluyendo el sexual. Japón un país de castas y de mercaderes, de prostitución y rickshaw, de una pobreza salvaje que bordea a una sociedad que funda sus bases económicas en el capitalismo triunfante de las décadas del 70 y 80 del siglo XX.

Japón trató de posesionarse de parte del mundo asiático, en la misma carrera imperialista que habían comenzado Gran Bretaña y Francia, mientras sonreía a sus clientes y mostraba su sensibilidad hacia la naturaleza, Japón avanzaba hacia China y Malasia. Una vez eliminado Japón como imperio, sus bases económicas y capitales permitieron desarrollar una economía ventajosa sobre sus competidores comerciales, los "nuevos países": Corea, Taiwán, China y Vietnam. Durante años los comerciantes, diplomáticos, nuevos ricos, aventureros, aparecen en Japón para exportar sus productos textiles y suvenires, así como sus particularidades culturales y gustos, este proceso bidireccional también generó importaciones inconcebibles dentro de Japón como un "lugar exótico"; en la medida en que crecen las relaciones comerciales, el pueblo japonés se moderniza y adquiere la última moda.

Casi al alcance de mi mano domino el arranque de Shingo-Machi, "la gran arteria de Kyoto" recta, ancha, por la que veo deslizarse la nube de "kurumas" como escuadrones de zompopos; en la que las tiendas, las más grandes, las de más lujo, las más famosas de toda la ciudad, van, seguramente, abriéndose una 
tras otra; en la que la multitud se afana se apretuja, transita sin estorbarse, sin codearse siquiera, cambiando incesantes sonrisas y ceremoniosas reverencias. (Ambrogi 1915: 100).

Las obras de encanto del Japón, como El Japón heroico y galante de Gómez Carrillo, o Nikko de Rebolledo, recientemente editadas, nos hacen pensar en la necesidad de mantener los lugares imaginarios. Si bien las obras de Pierre Loti, como Madame Crisantemo, han sido recientemente reproducidas, su crónica Japonería de Otoño solo tiene una edición en Español de 1889; en ella se percibe el desencanto del autor francés. Editar la obra de Ambrogi es descorrer el velo exótico que se alzó desde los primeros escritos de los jesuitas, Luís Froís o Engelbert Kaempfer, en el siglo XVIII; y que sigue explotándose comercialmente. Es posible que el Japón de Ambrogi no eline el velo, pero la metamorfosis kafkiana de las urbes japonesas y su banalidad agobiante, puede percibirse en la actualidad en cualquier calle de Sapporo, Tokio, Osaka o Kagoshima. Quienes vienen como turistas a Japón, encontrarán ese "lugar exótico" que reconocerán como "su Japón". Quienes vienen a descubrir la esencia de Japón, la podrán hallar en el corazón de una historia dispersa en cientos de productos culturales; quizás al regreso podrán decir algo con forma de Japón.

Hemos llegado al Imperial. Mi ensueño japonés se borra; la música de canciones y risas se apaga. En el hall espacioso, ante la mirada impasible del Mutus-hito de bronce que adorna la chimenea, están los ingleses, están los yanquis, están los alemanes; la raza de antipáticos turistas que lo infesta todo, que pone su mancha en el esplendor de todo paisaje. Voy a ellos. No hay remedio. Y sentado cerca de uno de los veladores de mimbre (jimportado de Europa!) tomo una de las tantas revistas de ilustraciones extrajeras que por ahí ruedan, y me pongo a hojearla, distraídamente, melancólicamente. (Ambrogi, 1915: 25).

Hace ya un siglo se editó Sensaciones de Japón y de la China, y en el presente Japón sigue llenando los imaginarios de la isla exótica, única e irrepetible llena de geishas y samuráis; aunque sea el país del mundo donde más carteras Vuitton se venden: tres de cuatro jóvenes japonesas poseen una. 


\section{Referencias}

Almazán, D. (2006) “Las exposiciones universales y la fascinación por el arte del Extremo Oriente en España: Japón y China”, en Artigrama (21): 85-104.

Ambrogi, A. (1912). Marginales de la vida. San Salvador, El Salvador: Talleres de Imprenta Nacional de San Salvador.

(1915). Sensaciones del Japón y de la China, San Salvador, El Salvador: Talleres de Imprenta Nacional de San Salvador.

(1962). Crónicas Marchitas, San Salvador, El Salvador: Dirección General de Publicaciones del Ministerio de Educación.

Barlés E. y Almazán V. (coords.) (2008) La mujer japonesa, realidad y mito. Zaragoza: Prensas Universitarias.

Benjamin, W. (2012). Libro de los pasajes. Madrid, España: Ediciones Akal.

Gómez Carrillo, E. (1906). De Marsella a Tokio. Paris, Francia: Casa Editorial Garnier.

(1907). El alma Japonesa. Paris, Francia: Cada Editorial Garnier. (2009). El Japón heroico y galante. La Coruña, España: Ediciones

del Viento.

(2011). El Japón heroico y galante. Valladolid, España: Ediciones de la Universidad de Valladolid.

Hearn, Lafcadio. (2009). Japón un intento de interpretación. Gijón, España: Satori Ediciones.

Loti, Pierre. (1889). Japonerías de otoño. Madrid, España: El Cosmo Editorial. Mirbeau, O. (2010). El Jardín de los suplicios. Jaén, España: El olivo azul editorial. Said, Edward. (2008). Orientalismo. Barcelona, España: Random House Mondadori. S.A.

Rebolledo, Efrén. (1910). Nikko. México, México: Tipografía Díaz de León.

Tinajero, Araceli (2002). Orientalismo en el modernismo hispanoamericano. Lafayette, Indiana, EE.UU.: Purdue University Press.

Unamuno, Miguel. (1968) "El problema religioso en el Japón”, en Obras completas de Don Miguel de Unamuno, (Tomo. III) Nuevos ensayos. Madrid: Editorial Escélicer. Págs. 1115-1120.

"Del patriotismo irreligioso", en Obras completas de Don Miguel de Unamuno, (Tomo. IX) Discursos y artículos, Madrid: Editorial Escélicer. Págs. 1555-1559. 